Paper published by the Structural Concrete Laboratory of EPFL

\begin{tabular}{|l|l|}
\hline Title: & $\begin{array}{l}\text { Analogy between Sustained Loading and Strain Rate Effects on the Nonlinear } \\
\text { Creep Response of Concrete }\end{array}$ \\
\hline Authors: & Tasevski D., Fernández Ruiz M., Muttoni A. \\
\hline Published in: & $\begin{array}{l}\text { 10th International Conference on Mechanics and Physics of Creep, Shrinkage, } \\
\text { http://ascelibrary.org/doi/abs/10.1061/9780784479346.141 }\end{array}$ \\
\hline DOI & $10.1061 / 9780784479346.141$ \\
\hline Pages: & $1187-1193$ \\
\hline City, country: & Vienna, Austria \\
\hline Year of publication: & 2015 \\
\hline Type of publication: & Peer reviewed conference paper \\
\hline
\end{tabular}

\begin{tabular}{|l|l|}
\hline Please quote as: & Tasevski D., Fernández Ruiz M., Muttoni A., Analogy between Sustained \\
& Loading and Strain Rate Effects on the Nonlinear Creep Response of Concrete, \\
& 10th International Conference on Mechanics and Physics of Creep, Shrinkage, \\
& and Durability of Concrete and Concrete Structures, Vienna, Austria, 2015, \\
& $1187-1193$.
\end{tabular}




\title{
Analogy between Sustained Loading and Strain Rate Effects on the Nonlinear Creep Response of Concrete
}

\author{
Darko Tasevski ${ }^{1}$; Miguel Fernández Ruiz ${ }^{1}$; and Aurelio Muttoni ${ }^{1}$ \\ ${ }^{1}$ Structural Concrete Laboratory, School of Architecture, Civil and Environmental \\ Engineering, Swiss Federal Institute of Technology Lausanne, EPFL IBETON, \\ Station 18, CH-1015 Lausanne, Switzerland. E-mail: darko.tasevski@epfl.ch
}

\begin{abstract}
This paper investigates the uniaxial compression behaviour of concrete under different strain rates and its relation to sustained loading. The aim is to observe the strain rate effect on the pre- and post-peak behaviour of concrete. In particular, the development of nonlinear creep strains for different strain rates has been investigated and compared to the sustained load behaviour. The development of creep strains is in accordance with the progress of cracking as observed by acoustic emissions. An analogy is found between the concrete compression behaviour under various strain rates and the concrete compression behaviour under sustained loads at different stress levels.
\end{abstract}

\section{INTRODUCTION}

A reliable prediction of the time-dependent elastic and inelastic behaviour of concrete subjected to high levels of sustained loads is essential to understand the internal stress redistributions and the potential long-term failures occurring in structural concrete members. This behaviour is usually referred to as the timedependent response of concrete, which is found to be nonlinear for stresses higher than $40 \%$ of the short-term concrete strength. Levels of stress above this threshold imply the development of inelastic creep strains (Fernández Ruiz et al. 2007), leading to redistribution of stresses occurring at different strain rates and at different locations in $\mathrm{r} / \mathrm{c}$ structural members.

Previous research on elevated sustained loads has shown that the delayed creep effects do not only concern the serviceability of concrete structures but also their load-bearing capacity (Kaltakci et al. 2007). Failure under a sustained load can occur in a period of several minutes to several months after loading, depending on the degree of loading $\left(\sigma / f_{c}\right)$. This phenomenon was initially investigated by Rüsch (1960), who concluded the existence of a critical degree of loading at which concrete is able to sustain over time without failing. He established the term "sustained load strength" referring to the stress at the critical degree of loading. According to Rüsch (1960), for a sustained load below the critical degree of loading concrete would reach the so called creep limit that is a maximal value of strain which could be obtained 
depending on the degree of loading. Above the critical degree of loading, concrete would fail after a certain time again depending on the degree of loading.

Most of the researchers have found that the sustained load strength of normal strength concrete amounts around $70 \%$ to $75 \%$ of the short term strength (Rüsch (1960); Ngab et al. (1981); Smadi et al. (1982)). According to the experimental evidence of Rüsch (1960), the sustained load strength should be independent of the concrete short term strength, but Ngab et al. (1981), Smadi et al. (1982) and Iravani et al. (1998) observed that for high strength concrete, the sustained load strength is about $80-90 \%$ of the short term strength. Smadi et al. (1982) and Iravani et al. (1998) have also investigated the time of failure under high leves of sustained strain. For concrete with short-term strength of 35-40 MPa, Smadi et al. (1982) observed failure of several specimens under a sustained load of $75 \%$ of the short-term strength after 49 days, whereas several other specimens didn't fail during 6 months. Similarly, Iravani et al. (1998) observed failure of high strength concrete (short-term strength of $65 \mathrm{MPa}$ ) after 30 days and 7 days for specimens under sustained load of $75 \%$ and $80 \%$ of the short term strength respectively.

As for the influence of loading and strain rates on concrete compressive behaviour, most of the research in the last decades has been focused on high strain rates in order to understand the influence of impact loads. However, not many studies could be found on the influence of low strain rates apart of the work of Rüsch (1960). Some phenomenological studies on the effect of loading rate on the concrete compressive behaviour have been performed by Fernández Ruiz et al. (2007). Fischer et al. (2014) studied the loading rate effect on the behaviour of cement paste at young age, but these results cannot be taken as a reference for mature concrete.

This paper investigates the uniaxial compression behaviour of concrete under different strain rates and its relation to sustained loading. The aim is to observe the strain rate effect on the pre- and post-peak behaviour of concrete. In particular, the development of nonlinear creep strains for different strain rates has been investigated and compared to the sustained load behaviour.

\section{EXPERIMENTAL STUDY}

For the study of the influence of different strain rates on the uniaxial concrete behaviour of concrete, the Structural Concrete Laboratory of the Swiss Federal Institute of Technology in Lausanne is equipped with a Schenck Hydroplus servohydraulic testing machine with capacity of $2.5 \mathrm{MN}$ and a custom-made steel frame which enhances the stiffness of the test setup. The testing machine is placed in a room with controlled temperature of $21 \pm 0.5^{\circ} \mathrm{C}$ and a relative humidity of $52 \pm 3 \%$. The tests are performed on concrete cylinders of size øxh $=160 \times 320 \mathrm{~mm}$. The longitudinal strain $\varepsilon_{3}$ is measured with three omega strain gages fixed on two steel rings with a distance of $250 \mathrm{~mm}$. The transversal strain $\varepsilon_{1}$ is measured with a steel ribbon dilatometer equipped with a linear variable differential transformer (LVDT). 
A set of specimens was tested under constant strain rates from $2 \cdot 10^{0}[\% / \mathrm{s}]$ to $2 \cdot 10^{-6}[\% / \mathrm{s}]$ (time to failure from 1 second to ca. 12 days), using concrete cylinders with a mean 28-day compressive strength of $30.6 \mathrm{MPa}$ (tested with the reference strain rate of $2 \cdot 10^{-2}[\% / \mathrm{s}]$, i.e. test duration about 100 seconds). The age of the concrete at the time of testing was about 10 months (refer to Table 1 for the strength of concrete tested at the reference strain rate of $\left.2 \cdot 10^{-2}[\% / \mathrm{s}]\right)$. The general stressstrain behaviour is presented in Figure 1 and the results are presented in Table 1:

Table 1. Main experimental results.

\begin{tabular}{|c|c|c|c|c|c|c|}
\hline $\begin{array}{c}\dot{\varepsilon}_{\text {pilotage }} \\
{\left[\mathrm{s}^{-1}\right]}\end{array}$ & $\begin{array}{c}t_{u, \text { expected }} \\
{[\mathrm{s}]}\end{array}$ & $\begin{array}{c}f_{c} \\
{[\mathrm{MPa}]}\end{array}$ & $\begin{array}{c}\varepsilon_{3 u} \\
{[\% 0]}\end{array}$ & $\begin{array}{c}t_{u} \\
{[\mathrm{~s}]}\end{array}$ & $\begin{array}{c}t_{u} \\
{[-]}\end{array}$ & $\begin{array}{c}\dot{\varepsilon} \\
{\left[\mathrm{s}^{-1}\right]}\end{array}$ \\
\hline $2 \mathrm{E}+00$ & 1 & 41.8 & 1.88 & 0.85 & $1 \mathrm{sec}$ & $2.2 \mathrm{E}+00$ \\
\hline $2 \mathrm{E}-01$ & 10 & 40.5 & 2.03 & 9.26 & $10 \mathrm{sec}$ & 2.2E-01 \\
\hline $2 \mathrm{E}-02$ & 100 & 38.7 & 2.01 & 98.6 & $100 \mathrm{sec}$ & $2.0 \mathrm{E}-02$ \\
\hline $2 \mathrm{E}-03$ & $1^{`} 000$ & 37.8 & 2.07 & $1^{`} 010$ & 17 & $2.0 \mathrm{E}-03$ \\
\hline $2 \mathrm{E}-04$ & $10^{`} 000$ & 37.1 & 2.36 & $11^{\prime} 800$ & $3 \mathrm{~h} 17^{\prime}$ & $2.0 \mathrm{E}-04$ \\
\hline $2 \mathrm{E}-05$ & $100^{`} 000$ & 36.5 & 2.61 & $113^{`} 000$ & $1 \mathrm{~d} 7 \mathrm{~h}$ & 2.3E-05 \\
\hline $2 \mathrm{E}-06$ & $1^{`} 000^{`} 000$ & 34.3 & 2.75 & $1^{`} 050^{`} 000$ & $12 \mathrm{~d} 4 \mathrm{~h}$ & 2.6E-06 \\
\hline
\end{tabular}
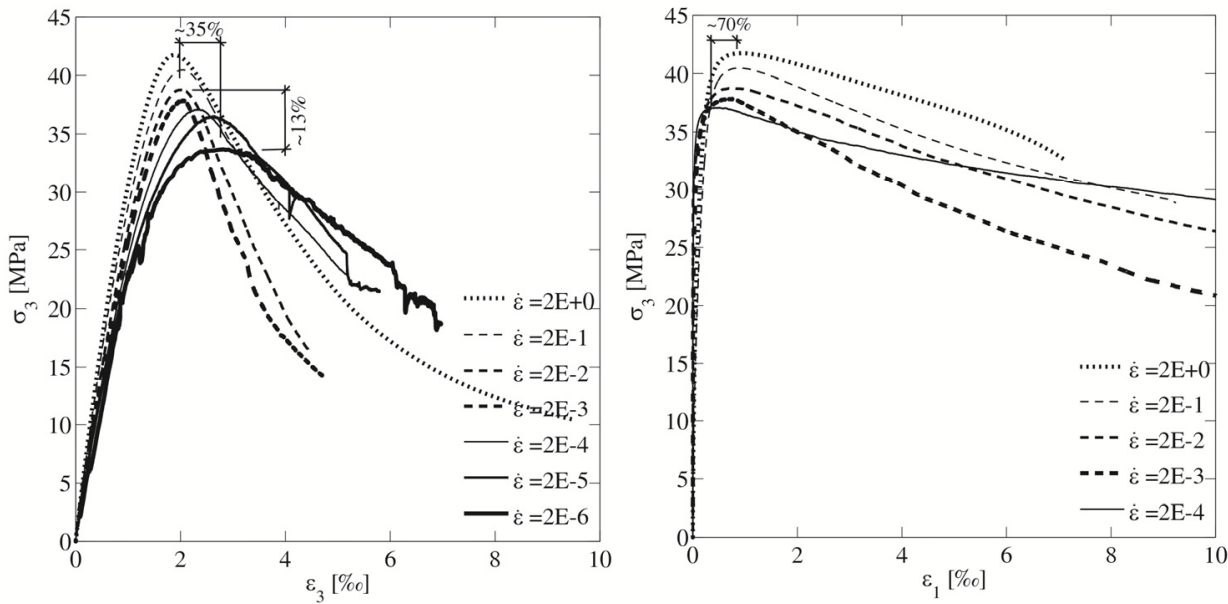

Figure 1. Stress-strain curves for longitudinal (left) and transversal strain (right).

The results of the experimental programme show that, with decreasing strain rate, the concrete strength reduces by about $13 \%$ (between the reference test of $100 \mathrm{~s}$ and the slowest test of ca. 12 days). The associated strain at failure in the longitudinal direction follows an increase of about $35 \%$ with decreasing strain rate. As for the transversal strain, a decrease is observed for decreasing strain rate. In addition, a less brittle behaviour of concrete is observed after peak load for decreasing strain rates (lower slopes at the post-peak softening branch). 
Acoustic Emission analysis was also performed during the tests in order to detect the development of cracks. An AE device with two piezoelectric sensors (frequency $100-1000 \mathrm{kHz}$ ) was used. The sensors were placed according to Figure 2. A pre-amplifier with a gain of $40 \mathrm{~dB}$ was used to amplify the signal. The detection threshold was set to $60 \mathrm{~dB}$ in order to filter the high environmental noise caused by the hydraulic testing machine. The AE results are presented in Figure 3.
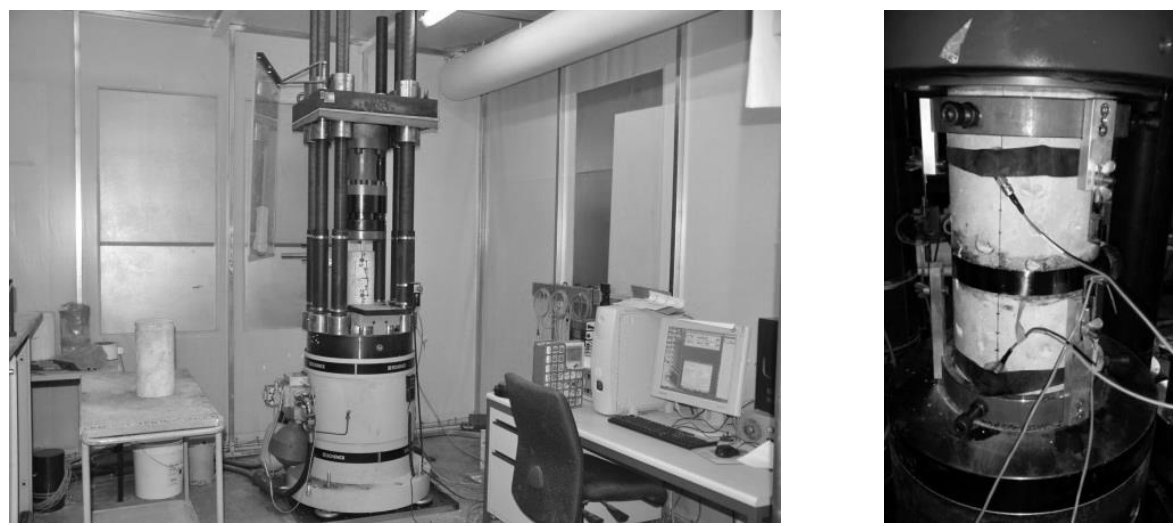

Figure 2. Servohydraulic testing machine (left). Position of the AE sensors (right).
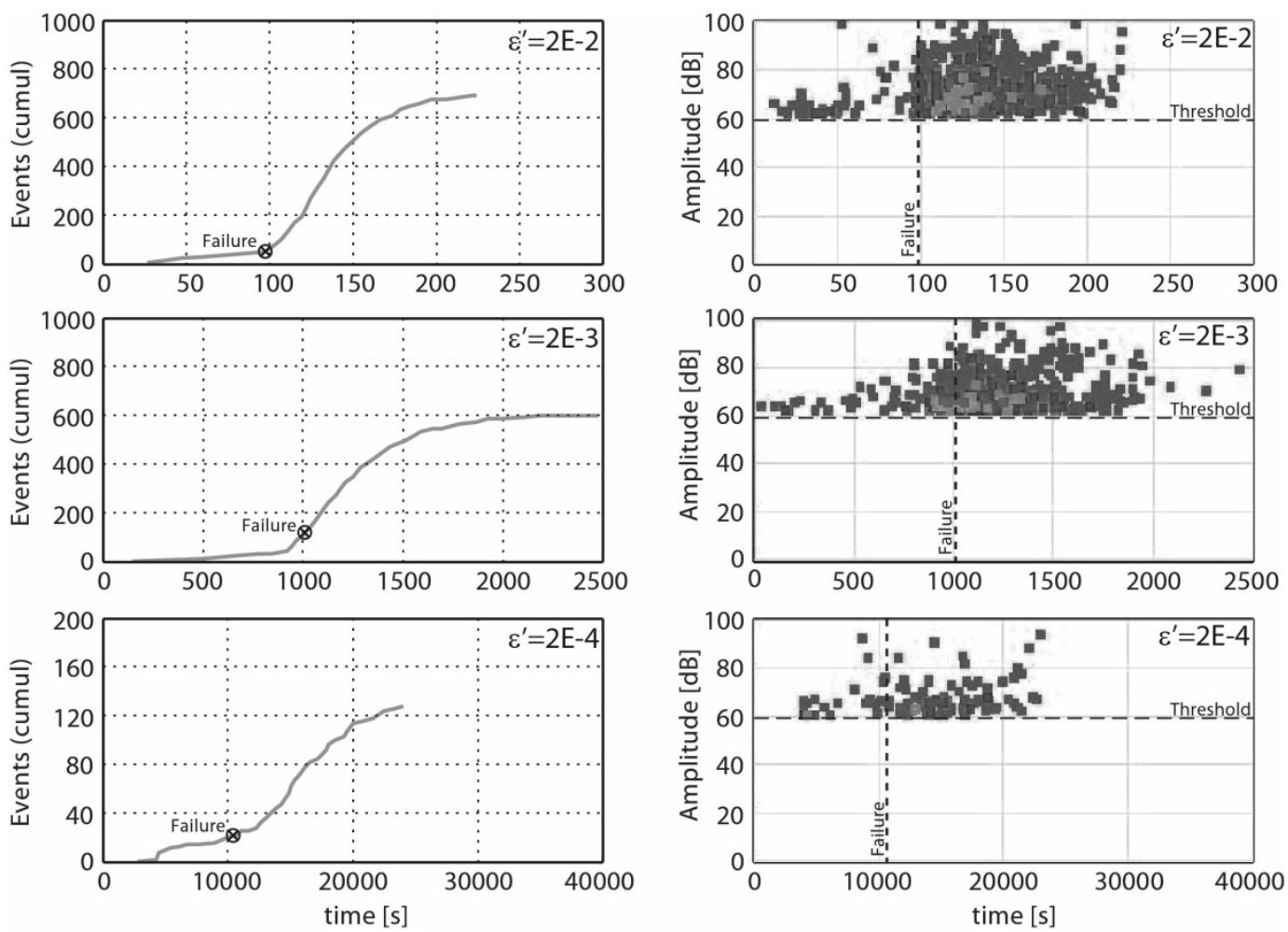

Figure 3. AE cumulative events and event amplitude distribution with time.

The development of creep strains is in accordance with the progress of cracking as observed by acoustic emissions (measurements performed on the specimens). The AE 
results indicate that for lower strain rates the rate of micro-cracking increases more rapidly. Especially in the domain of elevated stresses (near to failure) a significant increase in the cracking rate and the corresponding amplitudes of the observed events is detected.

\section{DISCUSSION OF RESULTS}

The decrease of strength for lower strain rates can be linked to the fact that for lower strain rates, the time to failure is larger and thus larger nonlinear creep strains can potentially develop (concrete is subjected to higher levels of stress during larger periods of time). Consequently, more micro-cracks can develop in the material leading to damage of the internal structure and reduction of the strength. A similar behaviour has been also observed by Fernández Ruiz et al. (2007), who found that the cracks at lower loading rates have enough time to open and to propagate similarly to pure creep tests.

As observed by the AE measurements, the increase in propagation of microcracks for elevated levels of stress seems to be in accordance with the development of nonlinear creep strains. Consistent with the explanation of Fernández Ruiz et al. (2007), the three different phases of nonlinear creep strain development could be observed, namely the crack formation, the stable crack growth and uncontrolled crack propagation up to failure associated with tertiary creep. The first two phases are indicated by the changes of inclination of the cumulative event curve for the tests with lower strain rates (Figure 3 left). The increase in the amplitude of the corresponding acoustic signals is associated with the acoustic energy dissipated at crack propagation. The increase of the amplitude indicates the increase of the cracking rate at the initiation of the third phase for elevated stress levels (Figure 3 right). Similar behaviour was observed by Rossi et al. (1994) for compressive creep and by Denarié et al. (2006) for tensile creep. Rossi et al. (1994) found that the basic creep strain is proportional to the number of micro-cracks created in the material. Denarie et al. (2006) indicated that the internal damaged caused by creep-induced micro-cracking should be taken into account when evaluating the long term benefits of concrete viscoelastic behaviour.

Finally, an analogy is found in the phenomenological compressive behaviour of concrete under various strain rates and under sustained loads at different levels. An ultimate strength envelope for the varying strain rate could be clearly observed from the experimental evidence, consistently to the sustained load strength envelope observed under sustained loads at different levels as shown by Rüsch (1960). Thanks to this analogy, the phenomenon of failure under sustained load can be investigated. However, further experimental observations are necessary in order to better understand the correlation between the behaviour of concrete under these two types of loading. 


\section{CONCLUSION}

This paper presents an experimental investigation on the influence of the strain rate on the uniaxial compressive behaviour of concrete. The main conclusions of this investigation are:

- Strain rate has a significant influence on the compressive strength and associated deformations of concrete.

- The concrete compressive strength decreases for decreasing strain rates.

- The longitudinal strain at peak load increases for decreasing strain rates.

- The transversal strain at peak load decreases for decreasing strain rates.

- The brittleness of concrete (defined as the area under the stress - longitudinal strain curve) after peak load increases for decreasing strain rates.

- Acoustic emissions confirm that the development of tertiary creep strains is related to the development of micro-cracking in concrete.

\section{ACKNOWLEDGEMENT}

The authors acknowledge the financial support from the Swiss Federal Roads Office.

\section{REFERENCES}

Denarié, E., Cécot, C. and Huet, C. (2006). "Characterization of creep and crack growth interactions in the fracture behavior of concrete", Cem. Concr. Res., vol. 36, no. 3, pp. 571-575, Mar. 2006.

Fernández Ruiz, M., Muttoni, A. and Gambarova, P. G. (2007). "Relationship between nonlinear creep and cracking of concrete under uniaxial compression," J. Adv. Concr. Technol., vol. 5, no. 3, pp. 383-393, 2007.

Fischer, I., Pichler, B., Lach, E., Terner, C., Barraud, E. and Britz, F. (2014). "Compressive strength of cement paste as a function of loading rate: Experiments and engineering mechanics analysis", Cem. Concr. Res., vol. 58, pp. 186-200, Apr. 2014.

Iravani, S. and MacGregor, J. G. (1998). "Sustained load strength and short-term strain behavior of high-strength concrete", ACI Materials Journal, vol. 95, no. 5, pp. 636-647, Sep.-Oct. 1998.

Kaltakci, M. Y., Arslan, M. H. and Ozturk, M. (2007). "Results and Lessons Learnt from the Buildings which Failed under their own Weight in Turkey. "Structural Engineering International, vol. 17, no. 2, May 2007, pp. 159-165

Ngab, A. S., Nilson, A. H. and Slate, F. O. (1981). "Shrinkage and Creep of HighStrength Concrete," ACI Journal, Proceedings, vol. 78, no. 4, pp. 255-261, July-Aug. 1981.

Rossi, P., Godart, N., Robert, J. L., Gervais, J. P. and Bruhat, D. (1994). "Investigation of the Basic Creep of Concrete by Acoustic Emission", Materials and Structures, vol. 27, no. 9, 510-514, Nov. 1994.

Rüsch H. (1960). "Researches Toward a General Flexural Theory for Structural Concrete," ACI Journal, Proceedings, vol. 57, no. 1, pp. 1-28, July 1960. 
Smadi, M. M., Slate, F. O. and Nilson, A. H. (1982). "Time-Dependent Behavior of High-Strength Concrete under High Sustained Compressive Stresses", Research Report, no. 82-16, Department of Structural Engineering, Cornell University, Ithaca, NY, 264 pp., Nov. 1982. 